\title{
Talep Şokları: Türk Turizm Sektörü İçin Bir Analiz
}

Demand Shocks: An Analysis for Turkish Tourism Sector

\author{
Kurtuluş BOZKURT*, Ozan BAHAR ** \\ *Yrd. Doç. Dr., Adnan Menderes Üniversitesi, Söke İşletme Fakültesi, Bankacılık ve Finans Bölümü, P. K. 09200, Söke, Aydın. \\ E-posta: kurtiboz_48@hotmail.com \\ **Prof. Dr., Muğla Sıtkı Koçman Üniversitesi, İktisadi ve İdari Bilimler Fakültesi, İktisat Bölümü, P.K. 48170, Kötekli, Muğla. \\ E-posta: obahar@mu.edu.tr
}

\section{MAKALE BILGILERI \\ Makale işlem bilgileri: \\ Gönderilme tarihi: 20 Şubat 2014 \\ Birinci değerlendirme: 16 Mart 2014 \\ İkinci değerlendirme: 25 Haziran 2014 \\ Kabul: 5 A ğustos 2014}

Anahtar sözcükler:

Turizm talebi, Talep şokları, Panel veri analizi.

\section{ARTICLE INFO}

Article history:

Submitted: 20 February 2014

Resubmitted: 16 March 2014

Resubmitted: 25 June 2014

Accepted: 5 August 2014

Key words:

Tourism demand, Demand shocks,

Panel data analysis.

\section{öz}

Bu çalışmanın amacı, Türk turizm sektöründeki talep şoklarının etkilerini analiz etmektir. Bu bağlamda Türkiye'ye en cok turist gönderen 24 ülke için T.C. Kültür ve Turizm Bakanlığının Turizm İstatistikleri veri tabanından elde edilen veriler ile 1991-2010 dönemini kapsayan bir panel veri seti olusturulmus ve panel birim kök analizleri yapıımıştır. Yapılan panel birim kök analizleri ile söz konusu şokların etkilerinin geçici mi yoksa kalıcı mı olduğu analiz edilmiștir. Yapılan panel birim kök analizleri sonucunda söz konusu talep şoklarının etkilerinin geçici olduğu sonucuna ulaşılmıștır. Bu kapsamda bu çalıșma Türk turizm sektöründe talep soklarının tanımlanması ve etkilerinin analizi noktasında öncül bir çalışma olma niteliği taşımaktadır.

\section{GiRiş}

Turizm, 21. yüzyılın en önemli hizmet sektörlerinden biridir. Bundan çok değil 50-60 yıl öncesine kadar, ekonomik önemi pek de fark edilmeyen turizm, bugün artık ister gelişmiş isterse az gelişmiş olsun tüm ülkeler için döviz geliri getiren önemli bir sektör konumundadır. Gelir kazandırıcı yönünün giderek artması ile birlikte, ülkelerin uluslararasi turizm piyasasından pay alma ve pazar arayışı ile bunun beraberinde getirmiş olduğu rekabet, özellikle Akdeniz bölgesinde her geçen gün artmaktadır (Bahar ve Kozak 2007; Kozak, Baloğlu ve Bahar 2010). Dolayısıyla ülkeler doğrudan yabancı sermaye yatırımları başta olmak üzere, bir takım teşvik, hibe, düşük faizli kredi ve desteklerle sektöre çok büyük yatırımlar yapmakta ya da çekmeye çalışmaktadır (Bahar 2010). Ancak ekonominin imalat öncelikli olmak üzere diğer sektörlerine oranla, turizme yapılan yatırımların geri dönüş süresi oldukça uzundur. Diğer bir deyişle, diğer sektörlere yapılan yatırımların geri dönüşü 3-5 yıl iken bu süre turizmde yedi ila 10 yıla kadar çıabilmektedir. Bu bağlamda, turizm sektörüne yapılacak olan yatırımların geri dönüşü ve sürdürülebilirliği sorunu, hem yatırımcı hem de ülke ekonomisi açısından düşünmeye değer bir konu olarak karşımıza çıkmaktadır. 
Diğer taraftan, turizm sektörü benzer şekilde ekonominin diğer sektörlerine göre bir takım şoklardan çok çabuk bir biçimde etkilenebilmektedir. Turizm sektörünü etkileyebilecek olan şokların değişik kaynakları ya da çeşitleri mevcuttur. Terör ve güvenlik olayları ile politik ve siyasi kargaşalar, ülkedeki güven ortamının bozulması, bulaşıcı ve salgin hastalıklar, doğal afetler, döviz kurlarında ve petrol fiyatlarında meydana gelen değişmeler, negatif arz-talep şokları ile birlikte ekonomik krizler bunlara örnek olarak verilebilir. Böylece çok büyük miktarlarda sabit sermaye yatırımlarının yapıldığ1 ve çok riskli bir yatırım alanı olarak görülen bu sektördeki şokların etkisinin kalıcı mı yoksa geçici mi olacağı sorusu akla gelmektedir. Eğer şokların etkisi kalıcı ise yapılan yatırımların geri dönüş süresi uzar ve turizmden elde edilmesi beklenen gelirler kaybedilebilir veya sağlanan kazançların sürdürülebilirliği tehlikeye girebilir. Tersi durumda yani şokların etkisi geçici ise ekonomik açıdan herhangi bir olumsuz durum söz konusu olmayacak, yapılan yatırımların geri dönüş süresi uzamayacak, turizmden beklenen gelirler elde edilebilecek ve sağlanan kazançların sürdürülebilirliği tehlikeye girmeyecektir.

Bu açıdan bakıldığında Türkiye'de turizm ekonomisi oldukça önemli bir yer tutmakla birlikte, 1980'li yıllardan itibaren sağlanan teşvik ve uygulanan politikalar ile turizm sektörü hızlı bir gelişme göstermiştir (Bahar 2006). 1980 yılında 1.288.000 olan yabanc1 turist sayısı 2010 yılında 27.000.000'a ulaşmıştır. Türkiye uluslararası ziyaretçi alımında \%2,9'luk payı ile dünya genelinde en çok turist alan altıncı ülke konumundadır. Turizm gelirlerindeki artış oransal olarak turist sayısındaki artış kadar fazla olmasa da 2010 yılı verilerine göre, uluslararası turizm piyasasindan elde edilen 20,8 milyar dolar gelirle Türkiye, dünya genelinde 10 . sırada yer almıştır (WTO 2011). Türkiye elde edilen turizm geliri siralamasında, 2010 yılında 10. Sirada iken 2014 yılında dünya genelinde ilk 10'a girememiştir (WTO 2014). 1998 yılında 736 ABD Dolarına ulaşan ortalama turist harcaması ise 2000 yılından itibaren bir düşüş eğilimine girerek 2010 yılında 755 ABD Doları olarak gerçekleşmiş, 2014 yılı rakamları ile ise ancak 828 ABD Dolarına çıkabilmiştir. Bununla birlikte sektörel olarak turizm Türkiye ekonomisi için en önemli gelir ve de döviz kaynaklarından biridir. 2009 yılında turizmin GSMH'deki yeri $\% 3,4$, toplam ihracat içindeki pay1 $\% 20,8$ olarak gerçekleşmiştir. Dış ticaret açığını kapatmaktaki rolü çok büyük olan turizm, tüm dünyada daralmanın yaşandığı 2009 yılında toplam dış ticaret açı̆̆ının \%54,79'unu, 2010 yılında ise \%29,08' ini tek başına kapatmıştır (www.tursab.org.tr).

Buradan hareketle, şokların yabancı turist sayısı ve harcamaları üzerindeki etkisinin kalıcı mı geçici mi olup olmadığının belirlenmesi, Türkiye'nin bu sektörden elde edeceği gelirlerin devam edip etmeyeceğinin ortaya konulması açısından büyük önem arz etmektedir. Çünkü Türkiye, mevcut yer altı/üstü kaynakları düşünüldüğü zaman öncelikle bir turizm ülkesi olarak değerlendirilmekte ve bu anlamda da sektöre hem ülke içinden hem de ülke dışından ciddi ölçüde yatırımlar yapılmaktadır. $\mathrm{Bu}$ yatırımların en az zararla geri dönmesi ve kâr sağlaması; ülkedeki işsizlik, dış ticaret açığı, ekonomik büyüme gibi temel makroekonomik sorunlara da çözüm olacaktır.

Bu bilgilerin ışığında yapılacak olan çalışmanın amac1, Türkiye'ye en çok turist gönderen 23 ülke için bir panel veri seti oluşturarak, şokların etkisinin kalıcı mı yoksa geçici mi olduğunu araştırmaktır. Bu kapsamda çalışmada öncelikle konu ile ilgili turizm alanyazını özetlenmiş, daha sonra çalışmanın veri seti ve analiz yöntemi açılandıktan sonra ulaşılan uygulama sonuçları yorumlanmıştır.

\section{ALANYAZIN INCELEMESI}

Turizm ekonomisi alanyazınında turizm sektöründeki olayların neden-sonuç ilişkisini açıklamakta kullanılan değişkenlerin durağanlık özelliğini inceleyerek, şokların ilgili değişkenlere ait seriler üzerindeki etkisinin kalıcı mı yoksa geçici mi olduğunu araştıran az sayıda da olsa bilimsel bazı araştırmalar mevcuttur. Bunlardan ilki Narayan'ın 2005 yılında Fiji için 1970-2002 yıllarını kapsayan çalışmasıdır. Narayan burada öncelikle "turist harcamaları" serisinin durağanlığını araştırmıştır. Genişletilmiş Dickey-Fuller testi serisinin durağan olmadığını, Zivot ve Andrews ile Lumsdaine ve Papell testleri ise askeri darbe dönemlerine denk gelen yapısal kırılmanın dikkate alınması halinde serinin durağan olduğunu göstermiştir. Narayan, 2005 yılında yine Fiji'deki 1987 yılında General Sitiveni Rabuka'nın yapmış olduğu askeri darbenin (şokun) ülkenin turist harcaması üzerindeki etkisinin kalıcı mı yoksa geçici mi olduğunu araştırdığı 
çalışmasında, 1970-2002 yıllarını kapsayan dönem için Vogelsang trend break testini kullanmıştır. Buna göre 1988 yılında yapısal bir kırılmanın olduğu sonucu ortaya çıkmakta, ancak daha sonraki dönemde Fiji'nin turist harcamaları üzerinde Rabuka darbesinin etkisinin geçici olduğu gözlenmektedir.

Bhattacharya ve Narayan (2005), 1980-1999 dönemi için Hindistan'a turist gönderen 10 ülkeden gelen turistlerin sayısını gösteren serilerin durağan olup olmadığını hem zaman serileri ve hem de panel birim kök veri analiziyle incelemeye çalışmışlardır. Panel birim kök veri analizi, serilerin durağan olduğunu gösterirken, zaman serisinde bunun tam tersi bir sonuç ortaya çıkmıştır. Doğal felaketler, Pakistan ve Hindistan arasındaki sınır ihlalleri gibi dışsal şokların Hindistan'a gelen ziyaretçiler üzerinde herhangi bir kalıcı etkisinin olmadığı yani serilerin durağan olduğu sonucuna varılmıştır. $\mathrm{Bu}$ faktörlerin, ülkenin turizm sektörü üzerindeki etkisi geçici ve kısa dönemlidir.

Eğer bir ülkeye olan ziyaretçi girişleri durağan değilse bu durumda şokların ziyaretçi sayıları üzerinde etkisi kalıcı olmaktadır. Bu bağlamda, ekonometrik olarak bakıldığında serilerde yapısal kırılmanın olması kısaca şok olarak tanımlanmaktadır. Diğer taraftan eğer ziyaretçi sayılarını gösteren serilerde bir durağanlık söz konusu ise bu durumda şokların ziyaretçi sayıları üzerindeki etkisi de geçici olacaktır.

Narayan'in 2008 yılında Avustralya'ya 28 ayrı ülkeden gelen ziyaretçilerin sayısını gösteren ve 1991-2003 dönemini kapsayan diğer bir çalışmasında serilerin durağanlığını incelemiş ve panel birim kök testleri serilerin durağan olduğunu göstermiştir. Bireysel birim kök testleri ise sadece yapısal k1rılmanın dikkate alındığı durumda bu sonucu desteklemiştir. Asya finansal krizi ve 11 Eylül terörist saldırıları gibi önemli iki yapısal kırılma durumunda Avustralya'ya diğer 28 ülkeden gelen ziyaretçi sayısında da \%79'luk bir düşüş gözlemlenmiştir.

Narayan ve Prasad'ın 2008 yilında Lee ve Strazicich birim kök testleri yardımıyla tek ve iki yapısal testlerini kullanarak dört Pasifik ülkesindeki reel efektif döviz kurlarının durağanlığını incelemişlerdir. Papua Yeni Gine ve Fiji için 1979-2003, Solomon Adaları için 1978-2004 ve Samoa için ise 1975-2003 yıllarına ait zaman serileri oluşturulmuştur. Elde edilen bulgulara göre Papua Yeni Gine ve Samoa için döviz kuru oranları durağan diğer bir deyişle, şokların reel döviz kurları üzerindeki etkisi geçici;
Fiji ve Solomon Adaları için ise durağan değil yani şokların etkisinin kalıcı olduğu sonucuna varılmıştır. Döviz kurlarının değişmesinin satın alma gücü paritesi üzerinde yarattığı etki kalıcı ise şokların etkisi kalıcl; eğer satın alma gücü paritesi üzerinde yaratılan etki geçici ise şokların etkisi de geçici olacaktır. Benzer şekilde, toplam talepte kalıcı bir kayma yaratıyorsa şokların etkisi kalıc1; toplam talebi kaydirmadan sadece dalgalanmaya neden oluyorsa şokların etkisi geçicidir.

Sivri'nin 2010 yılında Türkiye ekonomisi için yapmış olduğu 1963-2008 dönemini kapsayan çalışmasında; yabancı ziyaretçi sayısı, yabancı ziyaretçi harcamaları ve kişi başına yabancı ziyaretçi harcamalarının durağanlığ 1 incelenmektedir. Yapısal kırılmanın dikkate alınmadığı durağanlık testleri, yani Ng ve Perron tarafından geliştirilen M testleri, serilerin durağan olmadığını göstermektedir. Buna karşıllk bir ve iki yapısal kırılmaya izin veren durağanlık testleri kullanıldığında, sırasıyla Zivot ve Andrews ile Lee ve Strazicich birim kök testleri sonuçları tamamen değişmektedir. Bu durumda, test sonuçları serilerin yapısal kırılma(lar) ile durağan olduğunu ortaya koymaktadır.

Bu çalışmalara ilave olarak, Lean ve Smyth 2009 yılında 1995-2005 dönemi için Malezya'ya 10 farklı ülkeden gelen yabancı ziyaretçilerin sayısını gösteren serilerin, yapısal kırılmanın dikkate alınması durumunda durağan oldukları sonucunu elde etmişlerdir. Lee (2009) ve Smyth, Nielsen ve Mishra'nın (2009) yapmış oldukları benzer çalışmalarda da genel olarak serilerin durağan oldukları tespit edilmiştir.

Narayan 2011 yılında Avustralya için 1976-2004 yıllarını kapsayan başka bir çalışmasında teorik olarak geliştirilen bir makro model çerçevede ve iş çevrimlerini de dikkate alarak turist harcamaları ile GDP üzerindeki değişmeleri açıklamasında şokların geçici ya da kalıcı bir etkisinin olup olmadığını araştırmıştır. ARDL modelini kullandığ 1 çalışmasinda Narayan turizm harcamaları ve GDP arasında ortak trend ve döngüsellik ilişkisi bulmuştur. Ayrıca turizm harcamaları şoklarının geçici etkileri olduğu sonucuna ulaşmıştır.

\section{MODEL VE VERI SETi}

Bilindiği üzere iş çevrimleri teorilerinin temel yaklaşım noktası gelirdeki dalgalanmaların nedenlerini açıklamaya çalışmaktır. Diğer bir ifadeyle aşağı- 
daki denklemde de görüleceği üzere $Y_{t}-Y_{t-1}$ arasındaki değişmenin yani Y'deki değişmelerin nedenlerini belirlemektir.

$$
\Delta Y_{t}=Y_{t}-Y_{t-1}
$$

Ancak gelirdeki değişme $(\Delta Y)$ doğası gereği otoregresif bir süreci içerisinde barındırmaktadır. $\mathrm{Bu}$ otoregresif süreci aşağıdaki denklem ile göstermek mümkündür.

$\Delta Y_{t}=p \Delta Y_{t-1}+u_{t}$

Denklemde $u_{i}$, otoregresif süreçle bağlantılı olarak şokların etkilerini yansıtan hata terimini ifade etmektedir. Diğer taraftan $p ; p \in[0,1)$ koşulu altında sabit bir katsayıdır. Bu süreç dâhilinde pozitif bir şokun $\left(u_{i}>0\right)$ çıktı düzeyini arttıracağı buna karşın negatif bir şokun ise $\left(u_{i}<0\right)$ tam aksine çıktı düzeyini azaltacağını söylemek mümkündür.

Tabiî ki burada bahsedilen şok kavramı genel anlamda makro ekonomik bir şok tanımını içermektedir ve spesifik bir şok tanımının da yukarıdaki gösterimle benzer bir şekilde otoregresif bir süreci içereceği söylenebilir. Dolayısıyla bu çalışma için geçerli olacak otoregresif bir süreci içerisinde barındıran ve ortalaması sıfırdan farklı, normal dağılıma sahip hata terimi ile ifade edilen şok süreci aşağıdaki denklem ile ifade edilebilir.

$\ln \delta_{i t a, t}=\ln \delta_{i t a, t-1}+\varepsilon_{t}^{i t a}$

Denklemde $\ln \delta_{\text {itat. }}$ i ülkesindeki Türkiye'ye yönelik turizm talebini ve $\varepsilon_{t}^{i t a}$ da talep şokların etkilerini yansitan hata terimini ifade etmektedir.

Diğer taraftan çalışma kapsamında Türkiye'ye en çok turist gönderen 24 ülke için T.C. Kültür ve Turizm Bakanlığı'nın Turizm İstatistikleri veri tabanından elde edilen veriler ile 1991-2010 dönemini kapsayan bir panel veri seti oluşturulmuştur. İlk olarak verilerin logaritmik formları kullanılarak (3) numaralı denklemdeki regresyon modeli tahmin edilmiş ve her bir ülke ve yıl için talep şoklarının göstergesi olarak kullanılan değerleri $\varepsilon_{t}^{i t a}$ he- saplanmıştır (Ekler kısmına bakınız). İkinci aşamada ise öncelikle hesaplanan $\varepsilon_{t}^{i t a}$ değerleri için yatay kesit bağımlılığının olup olmadığı LMadj test istatistiği ile tespit edilmiştir.

\section{YÖNTEM}

Çalışmanın yöntem kısmında öncelikle seriler arasında yatay kesit bağımlılığının varlığına değinilmiştir. Zira seriler arasında yatay kesit bağımlılığ 1 nın varlığı uygulanacak birim kök testlerinin güvenilirliğini etkilemektedir. Bu noktada uygulamada eğer seriler arasında yatay kesit bağımlılı̆̆ 1 varsa birinci nesil panel birim kök testleri kullanılırken yatay kesit bağımlılı̆̆ının olmadığı durumda ise ikinci nesil panel birim kök testleri kullanılmaktadır.

Bu çalışma için yatay kesit bağımlılığının tespiti noktasında Pesaran (2004) tarafından BreuschPagan (1980) Lagrange Multiplier (LM) testinden hareketle elde ettiği sapması düzeltilmiş LM testi (LMadj) kullanılmıştır. Analiz sonucunda elde edilen LMadj test istatistiğinin olasılık değerinin $\% 5$ anlamlılık düzeyinde anlamlı olması ise paneli oluşturan birimler arasında yatay kesit bağımlılığ 1 nın olduğu sonucuna ulaştırmaktadır (Pesaran vd. 2008). Bu noktada ikinci nesil panel birim kök testlerini kullanmak analizin tutarlılı̆̆ 1 için daha doğru olmaktadır. Tablo 1'de ilgili LMadj test istatistiği sonucu verilmiş olup sonucun $\% 5$ anlamlılık düzeyinde anlamlı olması nedeniyle ikinci nesil testlerden CADF testinin kullanılması, ayrıca birinci nesil panel birim kök testlerinin uygulama sonuçlarının da çalışmada verilmesi kararlaştırılmıştır.

Bu bağlamda alanyazına bakıldığında uygulamada ilk kabul gören birinci nesil test Levin, Lin ve Chu Testi (LLC) olmuştur. Bu test Levin ve Lin'in (1992, 1993) çalışmalarına dayanmaktadır. Levin ve $\operatorname{Lin}(1992,1993)$ testi (LL) ise birim kök sinaması yaparken tüm yatay kesitleri tek bir kesit gibi değerlendirerek analiz yapmaktadır. Levin ve Lin'in bu yöntemi tercih etmelerinin nedeni ise test istatistiğinin anlamlılık gücünün daha yüksek çımasıdır. Analiz kapsamında ADF regresyonu dikkate alınmaktadır ve homojen panel birim kök varsayımı yapılmaktadır. Levin, Lin ve Chu Testi de benzer temel varsayımları dikkate almaktadır. Ancak her bir yatay kesit için ayrı bir ADF regresyonu tanımlanmaktadır. Testin varsayımları ile boş ve alternatif hipotezleri aşağıdaki gibidir. 
$\beta_{1}=\beta_{2}=\cdots \cdots=\beta_{N}=\beta$

$\operatorname{Cov}\left(u_{i, t}, u_{j, t}\right)=0$ ve $i \neq j$

Yukarıdaki temel varsayımlar altında;

$H_{0}: \beta_{1}=\beta_{2}=\cdots \cdot=\beta_{N}=0 \quad$ (Birim kök vardır, seri durağan değildir)

$H_{A}: \beta_{i}=\beta\langle 0 \quad$ (Birim kök yoktur, seri durağandır) hipotezleri test edilmektedir. Analizde kullanılan ve tahmin edilen temel regresyon modeli aşağıda belirtilen ADF regresyonudur.

$\Delta Y_{i, t}=\alpha_{i}+\beta_{i} Y_{i, t-1}+\delta_{i, t}+\sum_{j=1}^{p_{j}} \phi_{i, j} \Delta Y_{i, t-j}+v_{i, t}$

ve

$t=1,2, \ldots \ldots \ldots \ldots, T$ ve $i=1,2, \ldots \ldots \ldots \ldots, \Lambda$

Yukarıdaki ADF regresyon denkleminde; $i$ birden $N^{\prime} e$ kadar her bir bağımsız kesiti, $t$ de birden T'ye kadar zamanı ifade etmektedir. Analiz kapsaminda söz konusu panel homojendir ve her bir yatay kesit için elde edilen $\beta$ katsayısı aynıdır. Ayrıca paneli oluşturan bütün kesitler için gecikme sayıları da eşittir. $p$, ise gecikme derecesini ifade etmektedir ve her bir gecikme değeri AIC veya Schwartz bilgi kriterine göre belirlenmektedir. Levin, Lin ve Chu Testi dört aşamadan oluşmaktadır.

1. Aşama: $\Delta Y_{i, t}=\alpha_{i}+\delta_{i, t}+\sum_{i=1}^{p_{j}} \phi_{i, j} \Delta Y_{i, t-j}+e_{i, t}$ denkleminden $\hat{e}_{i, t}$ hesaplanir.

2. Aşama: $\Delta Y_{i, t-j}=\alpha_{i}+\delta_{i, t}+\sum_{j=1}^{p_{j}} \phi_{i, j} \Delta Y_{i, t-j}+v_{i, t} \quad$ denkleminden $\hat{v}_{i, t}$ hesaplanir.

3. Aşama: $: \widetilde{e}_{i, t}=\hat{e}_{i, t} / \hat{\sigma}_{\varepsilon i}{ }^{\prime}$ ve $: \widetilde{v}_{i, t}=v_{i, t} / \hat{\sigma}_{s i}$ heterojenlik düzeltmeleri yapilır.

$\hat{\sigma}_{s i}^{2}=\frac{1}{T-P_{i}-1} \sum_{t=p_{i}+2}^{T}\left(\hat{e}_{i, t}-\hat{\alpha}_{i} \hat{v}_{i, t-1}\right)$

4. Aşama: $\quad e_{i, t}=\alpha_{i} \hat{v}_{i, t}+\eta_{i, t}{ }^{\prime} d e n \quad \alpha_{i}$ tahmin edilir. Aşağ ${ }^{\prime}-$ daki $H_{o}$ ve $H_{A}$ hipotezleri altında $H_{o}$ hipotezi test edilir ve test istatistiği olarak $\mathrm{t}$ istatistiği kullanılır.

$\mathrm{H}_{\mathrm{o}}=\alpha=0$ (Birim kök vardır. Dolayısıyla seri durağan değildir)
$\mathrm{H}_{\mathrm{A}}=\alpha<0$ (Birim kök yoktur. Dolayısıyla seri durağandir)

$t_{\alpha}=\frac{\hat{\alpha}}{\operatorname{std} \cdot h t(\bar{\alpha})}$

$t_{\alpha}$ Standart normal dağılıma, sonlu ortalama ve varyansa sahiptir.

Alanyazında kabul gören ikinci önemli test ise Im, Pesaran ve Shin (IPS) testidir. Im, Pesaran ve Shin $(1997 ; 2003)$ yapmış oldukları çalışmalarda, homojenlik varsayımını esnek hale getirerek heterojen panel yapısına izin vermişlerdir. Testin boş ve alternatif hipotezlerine bakıldığında $H_{o}^{\prime}$ 'n diğer tüm panel birim kök testleri için ortak ancak $H_{A}$ hipotezinin sınırlandırıcı bir hipotez olduğu görülmektedir. Test aşağıdaki ADF regresyon denklemini dikkate almaktadır.

$\Delta Y_{i, t}=\alpha_{i}+\beta_{i} Y_{i, t-1}+\delta_{i, t}+\sum_{j=1}^{p_{j}} \phi_{i, j} \Delta Y_{i, t-j}+u_{i, t}$

$t=1,2, \ldots \ldots, T$ ve $i=1,2, \ldots \ldots, N$

Heterojen panel yaklaşımı.

$\operatorname{Cov}\left(u_{i, t}, u_{j, t}\right)=0$ ve $i \neq j$

Yukarıdaki temel varsayımlar altında;

$H_{0}: \beta_{i}=\beta=0 \quad$ (Bütün yatay kesitler için)

$H_{A}: \beta_{i}\langle 0 \quad$ (En az bir yatay kesit için)

Im, Pesaran ve Shin (2003) yapmış oldukları çalışma ile olabilirlik taslağını kullanmışlar ve eş zamanlı durağanlık ile durağan olmama durumunu dikkate alan ve $t$-bar istatistiği olarak tanımlanan bir birim kök testi ortaya koymuşlardır. Bu noktada öncelikle her bir kesit için birinci sıra kendisiyle bağlaşımlı katsayının $t_{i}$ istatistiklerini ve $t_{i}$ 'lerin ortalamasını kullanarak da Z-bar istatistiğini hesaplamışlardır.

$$
\begin{aligned}
& t_{i}=\frac{\beta_{i}}{\operatorname{std} \cdot h t\left(\beta_{i}\right)} \text { ve } \bar{t}=\sum_{i=1}^{N} t_{i} / N \\
& Z-\operatorname{Bar}=\frac{\sqrt{N}\left(\bar{t}-N^{-1} \sum_{i=1}^{N} E\left(t_{\beta_{i}}\right)\right.}{\sqrt{N^{-1} \sum_{i=1}^{N} \operatorname{var}\left(t_{\beta_{i}}\right)}} \sim N(0,
\end{aligned}
$$


Im, Pesaran ve Shin (2003) Z-bar istatistiğindeki $E\left(t_{\beta_{\mathrm{I}}}\right)$ ve $\operatorname{var}\left(t_{\beta_{\mathrm{I}}}\right)$ değerlerini Monte Carlo simülasyonları ile bulmuşlar ve bulmuş oldukları sonuçları tablolaştırmışlardır. Gerek LL gerekse IPS testleri $N \rightarrow \infty, N / T \rightarrow 0$, ve N'nin T'ye göre oldukça küçük olduğu panel veri analizleri için uygulama alanı bulmaktadir. Bu noktada Im, Pesaran ve Shin (1997) N'nin T'ye göre büyüdüğü durumlarda simülasyon sonuçlarının gerek LL gerekse IPS testleri için sorun teşkil edebileceğini vurgulamaktadır. Diğger taraftan IPS testi heterojenlik varsayımına karşın hangi kesitin durağan hangisinin durağan olmad1ğının tespiti hususunda bilgiler vermemektedir.

Bir diğger test ise IPS testinin devamı niteliğinde olan Maddala ve Wu'nun (1997) ortaya koymuş oldukları panel birim kök testidir. Maddala ve Wu testinin teorik olarak IPS testinin devamı niteliğinde olmasına karşın IPS testinden ayrılan tek yönü $\beta_{1}$ katsayılarının $\mathrm{t}$ istatistikleri yerine olasılık değerlerini $P_{i}$ kullanmasıdır. Maddala ve $\mathrm{Wu}$ testi Fisher tipi bir test olmakla birlikte, testin boş ve alternatif hipotezleri ile test istatistiği aşağıdaki gibidir.

$H_{0}: \beta_{1}=\beta=0$ (Bütün yatay kesitler için)

$H_{A}: \beta_{1}<0$ (En az bir yatay kesit için)

$P_{\lambda}=-2 \sum_{i=1}^{N} \ln \left(p_{i}\right) \sim \chi_{2 N}^{2}$

Testte panel veri birim köklerinin test edilebilmesi için her bir yatay kesite ait birim köklerin olasılık değerleri toplulaştırılmıştır. $P_{A}$ değerleri $2 N$ serbestlik derecesinde asimtotik olarak $\chi^{2}$ dağılımı göstermektedir. Ayrıca $T \rightarrow \infty$ ve $T>N$ iken Maddala ve $\mathrm{Wu}$ test istatistiğine bakmak çok daha anlamlı olmaktadır.

Maddala ve Wu testinin benzeri Fisher tipi bir test istatistiği ortaya koyan Choi (2001) $N \rightarrow \infty$ ve ile $N>T$ ile $N^{\prime}$ nin sonlu olduğu durumlar için iki farklı panel birim kök test istatistiği hesaplamıştır. Testin boş ve alternatif hipotezleri IPS testinin boş ve alternatif hipotezleri ile aynıdır.

$N \rightarrow \infty$ gitmesi ve $N>$ T durumund $x_{r}=-N^{-1 / 2} \sum_{i=1}^{N} \ln \left(p_{i}+1\right) \sim N(0,1)$ test istatistiği hesaplanmaktadır ve $N$ büyüdükçe test istatistiğinin de gücü artmaktadır.

$N^{\prime}$ nin sonlu olduğu durumda ise $Z=N^{-1 / 2} \sum_{i=1}^{N} \phi^{-1}\left(p_{i}\right)^{a s y} \sim N(0,1)$ test istatistiği hesaplanmaktadır ve $\phi$ standart normal dağılım fonksiyonudur. $P_{1}$ değeri $0 \leq P_{1} \leq 1$ ara- sında değerler almaktadır. Dolayısıyla $\phi_{-1}\left(\mathrm{P}_{1}\right)$ değişkeni normal dağılıma sahip rassal bir değişkendir ve $T \rightarrow \infty$ iken tüm kesitler için geçerlidir (Choi 2001). Z testi asimtotik olarak standart normal dağılıma sahiptir ve bazı durumlarda IPS testine göre çok daha anlamlı test sonuçları verdiği için Baltagi ve Kao (2000) tarafından da tavsiye edilen önemli bir panel birim kök test istatistiğidir.

Tüm bu çalışmalardan farklı olarak Hadri (2000) tüm kesitler için zaman serilerinin deterministik bir trend etrafında durağan olduğunu vurgulayan boş hipotezi ve birim kök içerdiğini vurgulayan alternatif hipotezi test eden artık temelli bir LM testi önermiştir. Hadri (2000) testi önceki testlerden farklı olarak zaman serilerinin durağanlığını test eden Kwiatkowski-Phillips-Schmidt-Shin (KPSS) testinin panel veriler için geliştirilmiş şeklidir. Test trendli ve trendsiz model olmak üzere iki temel model kullanmaktadir.

$y_{i, t}=\beta_{i, t}+u_{i, t} \quad$ (Trendsiz model)

$y_{i, t}=\beta_{i, t}+\delta_{i} t+u_{i, t} \quad$ (Trendli model)

Denklemlerde $\beta_{i, t}=\beta_{i t-1}+e_{i, t}$ ve $t=1,2, \ldots \ldots . ., T$ ve $i=1,2, \ldots \ldots ., N$ 'dir

$u_{i, t}$ ve $e_{i, t}$ karşılıklı ve özdeş dağılmaktadır.

$E\left(u_{i, t}\right)=0$ ve $E\left(u_{i, t}^{2}\right)=\sigma_{u}^{2}>0$

$E\left(e_{i, t}\right)=0$ ve $E\left(e_{i, t}^{2}\right)=\sigma_{e}^{2} \geq 0$

Trendli ve trendsiz modeller için boş ve alternatif hipotezler ise $H_{0}: \sigma_{e}^{2}=0$ ve $H_{A}: \sigma_{e}^{2}>0$ 'dir. Trendli ve trendsiz modeller geriye doğru iterasyonla çözüldüğünde aşağıdaki denklemler elde edilmektedir.

$y_{i, t}=\beta_{i, 0}+\sum_{t=1}^{T} e_{i, t}+u_{i, t}=\beta_{i, 0}+\varepsilon_{i, t} \quad$ (Trendsiz model)

$y_{i, t}=\beta_{i, 0}+\delta_{i} t+\sum_{t=1}^{T} e_{i, t}+u_{i, t}=\beta_{i, 0}+\delta_{i} t+\varepsilon_{i, t} \quad$ (Trendli model) (11)

Bu noktada; durağanlık ön savının sınanması aşamasında $u_{i, t}$ 'lerin paneli oluşturan yatay kesitler arasında sabit varyanslı mı (uzun dönem varyansı homojen) yoksa değişen varyanslı mı (uzun dönem varyansı heterojen) oldukları varsayımı altında iki farklı $L M$ istatistiği $\left(L M_{H m}, L M_{H M}\right)$ aşağıdaki şekilde hesaplanmaktadır. 
$L M_{H M}=\frac{N^{-1} \sum_{i=1}^{N} T^{-2} \sum_{t=1}^{T} s_{t, T}^{2}}{\hat{\sigma}_{u}^{2}}$ and $s_{i, t}=\sum_{j=1}^{t} \hat{u}_{i, j} ; \hat{\sigma}_{u}^{2} \sum_{i=1}^{N} \sum_{t=1}^{T} \hat{u}_{i, t}^{2}$

$L M_{H T}=\frac{N^{-1} \sum_{i=1}^{N} T^{-2} \sum_{t=1}^{T} s_{i, T}^{2}}{\hat{\sigma}_{u, i}^{2}}$

$L M_{H T}$ denklemindeki $\hat{\sigma}_{u, i}^{2}$ ifadesi her bir yatay kesit için değişen varyans varsayımı altında ayrı ayrı hesaplanmaktadır. Bu bağlamda Hadri (2000) sirasiyla trendli ve trendsiz model için $L M$ istatistiklerinin limit dağılımlarını ise aşağıdaki şekilde göstermektedir.

$Z_{\mu}=\frac{\sqrt{N\left(L M_{\mu}-\psi_{\mu}\right)}}{\phi_{\mu}} \sim N(0,1)$

$Z_{\tau}=\frac{\sqrt{N\left(L M_{\tau}-\psi_{\tau}\right)}}{\phi_{\tau}} \sim N(0,1)$

Formüllerdeki $\psi_{\mu}$ ifadesi $z_{\mu}$ rassal değişkeninin ortalamasıdır ve $1 / 6$ değerine eşittir. $\phi_{\mu}^{2}$ ifadesi ise $Z_{\mu}$ rassal değişkeninin varyansıdır ve $1 / 45$ değerine eşittir. Diğer taraftan $\psi_{\tau}$ ifadesi $Z_{\tau}$ rassal değişkeninin ortalamasıdır ve $1 / 15$ değerine eşittir. $\phi_{\tau}{ }_{\tau}$ ifadesi ise $Z_{\tau}$ rassal değişkeninin varyans1dır ve 11/6300 değerine eşittir. Eğer yapılan analiz sonucunda $L M_{H M ; H T}>L M_{\text {kiritik }}$ sonucuna ulaşılırsa $H_{0}$ hipotezi reddedilir. Başka bir ifadeyle verilerin durağan olmadığı sonucuna ulaşılır.

Yatay kesit bağımlılığı altında panel birim kök s1naması yapan bir diğer çalışma ise Peseran (2006) tarafından geliştirilen ikinci nesil CADF sınamasıdır. Yapılan simülasyonlar sonucunda gerek $N \rightarrow \infty$ gerekse $T>N$ ve $N>T$ durumları için geçerli ve anlamlı istatistiksel sonuçlara ulaştığ 1 görülmüştür. Im, Peseran \& Shin $(1997 ;$ 2003)'nin çalışmalarındakine benzer şekilde aşağıdaki temel ADF denkleminden hareketle tüm seriler için ortak ve her seri için ayrı ayrı tanımlanan seriye özgü iki fark11 kısımdan oluşan bir hata terimi tanımlaması yapılmıştır. Diğer bir deyişle yatay kesit bağımlılığ altında mekânsal korelasyonda dikkate alınmıştır.

$\Delta Y_{i, t}=\alpha_{i}+\beta_{i} Y_{i, t-1}+\delta_{i, t}+\sum_{j=1}^{p_{j}} \phi_{i, j} \Delta Y_{i, t-j}+u_{i, t}$

$u_{i, t}=\lambda_{i} f_{t}+\varepsilon_{i, t} ; t=1,2, \ldots \ldots \ldots \ldots ., T$ ve $i=1,2, \ldots \ldots \ldots \ldots, N$
Denklemlerde $\lambda_{1}$ ifadesi her bir kesite ilişkin bağımsız zaman etkisini ifade etmektedir ve şok ve/ veya kriz gibi dışsal süreçlerin varlığında her bir kesit için söz konusu şok ve/veya kriz gibi dışsal süreçlerin etkilerinin farklı olacağını ifade etmektedir. Denklemdeki $f_{1}$ ifadesi ise tüm kesitler için ortak gözlenemeyen zaman etkisini ifade etmektedir ve durağan olduğu varsayılmaktadır. Denklemdeki $\varepsilon_{i, t}$ değeri her bir kesite ilişkin hata terimini ifade etmektedir ve kesitten kesite farklılık gösteren özdeş dağılmış bir değerdir.

CADF testinin boş ve alternatif hipotezleri ise aşağıdaki gibidir ve SURADF testindekine benzer şekilde tüm kesitler için ayrı ayrı hesaplanmış olan $\beta$ katsayılarına ilişkin $t$ değerleri kritik değerler ile karşılaştırılmaktadır. CADF testinin kullanmış olduğu ADF denklemi aşağıdaki gibidir ve $N \rightarrow \infty$ iken denklem EKK ile tahmin edilmekte ve hangi kesitlerin durağan olduğuna ve/veya durağan olmadığına karar verilmektedir.

$\Delta Y_{i, t}=\alpha_{i}+\beta_{i} Y_{i, t-1}+\sum_{j=1}^{p_{j}} c_{i, j} \Delta Y_{i, t-j}+d_{i} t+h_{i} \bar{y}_{t-1}+\sum_{j=0}^{p_{i}} \eta_{i, j} \Delta \bar{y}_{i, t-j}+\varepsilon_{i, t}$

1) $H_{0}^{i}: \beta_{i}=0$

2) $H_{A}^{i}: \beta_{i}\langle 0$ ve $i=1,2, \ldots \ldots \ldots \ldots, N$

$t_{i}=\frac{\hat{\beta}_{i}}{\operatorname{Sht}\left(\beta_{i}\right)}=C A D F_{i}$

SURADF testinden farklı olarak $C A D F$ testinde kritik değerler Peseran (2006) tarafından yapılan simülasyon sonuçları ile tablolaştırılmıştır. $N>T$ durumu için aşağıda da gösterilmiş olan $C A \bar{D} F$ istatistiği hesaplanmaktadır ve bu istatistiğe CIPS istatistiğ de denilmektedir. $C A \bar{D} F$ ve/veya CIPS istatistiğinin durumu içinde iyi sonuçlar verdiği $T>N$ görülmektedir.

$C A \bar{D} F=C I P S=\frac{\sum_{i=1}^{N} C A D F_{i}}{N}$

Her bir kesit için durağanlık sınaması yapılmasının temel mantığ 1 şokların seriler üzerindeki kalıcı ve geçici etkilerinin her bir kesit için sınanmak istenmesidir. Zira şoklar geçici ise seriler durağan olacak, tersi durumda seriler durağan değilse seriler durağan olmayacaktır. Dolayısıyla bu noktada her bir kesit için durağanlık sınaması yapmak kaçınılmaz olmaktadır. 
Gerek SURADF gerekse CADF testleri yatay kesit bağımsızlığı varsayımı altında geliştirilen testlerdir ve bu noktada öncelikle yapılması gereken kesitler arasında bir bağımlılık ilişkisinin olup olmadığının test edilmesidir. Bu bağlamda zaman ve kesit boyutunun farklı varyasyonları için üç farklı $L M$ test istatistiği hesaplanmaktadır. Bunlardan ilki N'nin sabit ve $\mathrm{T} \rightarrow \infty$ durumu için geliştirilen Breusch \& Pagan (1980)'nın LM testinin panel uygulaması olan $C D L M_{1}$ test istatistiğidir ve kesitler arasında ilişki yoktur boş hipotezi altında aşağıdaki gibi hesaplanmaktadır.

$C D L M_{1}=T \sum_{i=1}^{N-1} \sum_{j=i+1}^{N} \hat{\rho}_{i, j}^{2} \sim X_{N(N-1) / 2}^{2}$

Formüldeki $\hat{\rho}_{i, j}$ ifadesi her bir kesite ilişkin denklemlerin EKK tahmini ile elde edilen artıklar arasındaki yatay kesit korelasyonlarının tahminleridir ve $C D L M_{1}$ testi ile $\hat{\rho}_{t_{i}}$ 'ler arasinda korelasyon olmadığı boş hipotezi sınanmaktadır. $\hat{\rho}_{, j}$ 'ler ise aşağıdaki şekilde hesaplanmaktadır (Yılgör 2008).

$\hat{\rho}_{t, j}=\hat{\rho}_{j, t}=\frac{\sum_{t=1}^{T} \hat{u}_{t, t} \hat{u}_{j, t}}{\sqrt{\sum_{t=1}^{T} \hat{u}_{t, t}^{2} \sqrt{\sum_{t=1}^{T} \hat{u}_{j, t}^{2}}}}$

İkinci test istatistiği ise aynı anda hem $\mathrm{N} \rightarrow \infty$ hem de T $\rightarrow \infty$ durumu için Peseran (2004) tarafından geliştirilen kesitler arasında ilişki yoktur boş hipotezi altında normal dağ 1 lıma sahip $C D L M_{2}$ test istatistiğidir ve aşağıdaki şekilde ifade edilmektedir.

$C D L M_{2}=\sqrt{\frac{1}{N(N-1)}} \sum_{i=1}^{N-1} \sum_{j=i+1}^{N}\left(T \hat{\rho}_{i, j}^{2}-1\right) \sim N(0,1)$

Üçüncü test istatistiği ise $N>T$ durumu için yine Peseran (2004) tarafından geliştirilen kesitler arasında ilişki yoktur boş hipotezi altında normal dağılıma sahip $C D$ test istatistiğidir ve aşağıdaki şekilde hesaplanmaktadır.

$C D=\sqrt{\frac{2 T}{N(N-1)}}\left(\sum_{i=1}^{N-1} \sum_{j=i+1}^{N} \hat{\rho}_{i, j}\right)^{a s y} \sim N(0,1)$

Gerek birinci nesil panel birim kök testleri gerekse şu ana kadar anlatılmış olan ikinci nesil panel birim kök testleri veri üretme sürecinde yapısal k1rılmaların yaşanmadığını varsaymakta ve sürecin doğrusal bir süreç olduğu vurgulanmaktadır. Ancak zaman serisi analizinde de hatırlanacağı üzere yapısal kırılmalar dikkate alınmadığında DickeyFuller tipi zaman serisi birim kök testlerinin boş hipotezi ret etme sıklığı düşmektedir ve aynı sorun panel birim kök testleri içinde geçerli olmaktadır.

\section{UYGULAMA SONUÇLARI}

Çalışmanın uygulama kısmında öncelikle yatay kesit bağımlılığının tespiti için $L M_{a d j}$ test istatistiği sonuçlarına bakılmıştır ve aşağıda Tablo 1'de ilgili test istatistiği sonucu verilmiştir. Tablo 1'de ilgili $L M_{a d j}$ test istatistiği sonucunun $\% 5$ anlamlılık düzeyinde anlamlı olması nedeniyle birinci nesil panel birim kök testlerinin kullanılması kararlaştırılmıştır.

Bu kapsamda sırasıyla; LLC, Hadri, IPS, FisherADF ve Fisher-PP birim kök analizleri yapılmıştır. Her bir analize ilişkin sabitli ile sabitli ve trendli modellere ilişkin uygulama sonuçları ise sırasıyla; Tablo 2, Tablo 3, Tablo 4 ve Tablo 5'te verilmiştir.

Tablo 2'ye bakıldığında LLC panel birim kök analizi sonucunda gerek sabitli model gerekse sabitli ve trendli model kapsamında $\% 1$ ve $\% 5$ anlamlılık düzeylerinde, serilerin düzeyde birim köke sahip olduğu hipotezinin reddedildiği görülmektedir. Dolayısıyla LLC panel birim kök analizi sonuçlarına göre Türk turizm sektöründeki talep şoklarının etkilerinin geçici olduğu sonucuna ulaşılmaktadır.

Tablo 3'e bakıldığında ise Hadri panel birim kök analizi sonucunda gerek sabitli model gerekse sabitli ve trendli model kapsaminda $\% 1$ ve $\% 5$ anlamlılık düzeylerinde, serilerin düzeyde birim köke sahip olduğu hipotezinin reddedildiği görülmektedir. Dolayısıyla Hadri panel birim kök analizi sonuçlarına da Türk turizm sektöründeki talep şoklarının etkilerinin geçici olduğu sonucunu doğrulamaktadir.

Tablo 1. Yatay Kesit Bağımlılığı Test Sonuçları

\begin{tabular}{ll}
\hline LMadj Test Istatistiği & Prob. \\
\hline 3743.03 & 0.000 \\
\hline
\end{tabular}

Tablo 2. LLC Panel Birim Kök Test Sonuçları

\begin{tabular}{lcc}
\hline LLC & Istatistiği & Prob. \\
\hline Sabitli & -7.41294 & 0.0000 \\
\hline Sabitli ve Trendli & -5.57761 & 0.0000 \\
\hline
\end{tabular}


Tablo 3. Hadri Panel Birim Kök Test Sonuçları

\begin{tabular}{lrr}
\hline & Hadri Test İstatistiği & Prob. \\
\hline Sabitli & 6.08118 & 0.0000 \\
\hline Sabitli ve Trendli & 7.38635 & 0.0000 \\
\hline
\end{tabular}

IPS panel birim kök analizi sonuçlarına bakıldığında ise Tablo 4'te gerek sabitli model gerekse sabitli ve trendli model kapsaminda $\% 1$ ve $\% 5$ anlamlılık düzeylerinde, serilerin düzeyde birim köke sahip olduğu hipotezinin reddedildiği görülmektedir. Dolayısıyla IPS panel birim kök analizi sonuçları yine Türk turizm sektöründeki talep şoklarının etkilerinin geçici olduğu sonucunu doğrular niteliktedir.

Fisher-ADF ve Fisher-PP birim kök analizi sonuçlarına bakıldığında ise Tablo 5'te gerek sabitli model gerekse sabitli ve trendli model kapsaminda $\% 1$ ve $\% 5$ anlamlılık düzeylerinde, serilerin düzeyde birim köke sahip olduğu hipotezinin reddedildiği görülmektedir.

Son olarak ikinci nesil panel birim kök testi olan CADF test sonuçlarına bakıldığında ise Tablo 6'da serini düzeyde durağan olduğu görülmektedir. Diğer bir ifadeyle \%1 ve \%5 anlamlılık düzeylerinde, serilerin düzeyde birim köke sahip olduğu hipotezinin reddedildiği görülmektedir. Dolayısıyla ge-

Tablo 4. IPS Panel Birim Kök Test Sonuçları

\begin{tabular}{lrr}
\hline & IPS Test İstatistiği & Prob. \\
\hline Sabitli & -7.62701 & 0.0000 \\
\hline Sabitli ve Trendli & -5.57245 & 0.0000 \\
\hline
\end{tabular}

Tablo 6. CADF Panel Birim Kök Test Sonuçları

\begin{tabular}{rrrrrrr}
\hline & $t$-bar & $c v 10$ & $c v 5$ & cv1 & Z[t-bar] & Prob. \\
\hline Düzey & -2.890 & -2.070 & -2.150 & -2.320 & -5.407 & 0.000 \\
\hline
\end{tabular}

rek birimci nesil LLC, Hadri, IPS, Fisher-ADF ve Fisher-PP panel birim kök analizi sonuçları gerekse ikinci nesil CADF panel birim kök analizi sonuçları Türk turizm sektöründeki talep şoklarının etkilerinin geçici olduğu sonucunu doğrulamaktadır.

\section{SONUÇ}

Dünyada hızlı bir gelişme trendi gösteren turizm sektörünün, Türkiye'de de dünyadaki gelişmelere paralel olarak, hızlı bir gelişme trendi gösterdiği görülmektedir. WTO yapmış olduğu ileriye yönelik tahminlerde, turizmin 21. yüzyılda daha da büyük gelişmeler göstereceğini ifade etmektedir. 2020 yılında ise tüm dünya genelinde oluşacak turizm gelirlerinin 2 trilyon Dolara ulaşacağ 1 düşünülmektedir. Dolayısıyla Türkiye'de hükümetlerin ve sektör temsilcilerinin bu sektöre gereken önemi vermeleri ve uluslararası turizm piyasasında oluşacağ politikaları hızla üretmeleri gerekmektedir (Bahar ve Bozkurt 2010).

Özellikle Türkiye'de, ekonomik büyümenin gerçekleştirilebilmesi için alternatif bir araç olarak görülen turizm faaliyetleri her geçen gün önemini arttırmaktadır. Ayrıca turizm, ekonomik gelişme açısından ihtiyaç duyulan kaynak ve döviz finansmanının karşılanması, istihdam, üretim ve ödemeler dengesine sağladığ de diğer sektörlere sağlamış olduğu dışsallıklardan

Tablo 5. Fisher-ADF ve Fisher-PP Panel Birim Kök Test Sonuçları

\begin{tabular}{|c|c|c|c|}
\hline & & Fisher-ADF & Prob \\
\hline \multirow[t]{2}{*}{ Sabitli } & ADF-Fisher ki-kare & 145.707 & 0.0000 \\
\hline & ADF - Choi Z-stat & -7.23301 & 0.0000 \\
\hline \multirow[t]{3}{*}{ Sabitli ve Trendli } & ADF-Fisher ki-kare & 108.908 & 0.0000 \\
\hline & ADF - Choi Z-stat & -5.42813 & 0.0000 \\
\hline & Fisher-PP & Prob. & \\
\hline \multirow[t]{2}{*}{ Sabitli } & PP-Fisher ki-kare & 227.593 & 0.0000 \\
\hline & PP - Choi Z-stat & -9.06807 & 0.0000 \\
\hline \multirow[t]{2}{*}{ Sabitli ve Trendli } & PP-Fisher ki-kare & 134.184 & 0.0000 \\
\hline & PP - Choi Z-stat & -6.25319 & 0.0000 \\
\hline
\end{tabular}


dolayı ekonomik kalkınma ve büyümede önemli bir sektör olarak önemini arttırmaktadır (Gökovalı ve Bahar 2006; Bahar ve Bozkurt 2010).

Bunun yanında turizm, istihdamı geliştirmede, yoksulluğun azaltılmasında ve yoksullukla mücadelede, insanların kendilerini geliştirerek bu sektör aracılı̆̆ıyla refah seviyelerini arttırmada etkili olan bir sektör görünümündedir. Bu yönüyle turist harcamaları yerel ekonomiye katkı sağlamakta ve bölgesel olarak bakıldığında da turizm potansiyeline sahip yerlerin gelişmesine yardımcı olmakta ve bölgelerarası gelişmişlik farklarının giderilmesinde alternatif bir araç olarak karşımıza çıkmaktadır (Bahar ve Bozkurt 2010).

Diğer taraftan, turizm sektörü terör ve güvenlik olayları ile politik ve siyasi kargaşalar, ülkedeki güven ortamının bozulması, bulaşıcı ve salgın hastalıklar, doğal afetler, döviz kurlarında ve petrol fiyatlarında meydana gelen değişmeler, ekonomik krizler gibi arz ve talep şoklarından çok çabuk etkilenebilen bir sektördür. Bu noktada çok büyük miktarlarda sabit sermaye yatırımlarının yapıldığı ve çok riskli bir yatırım alanı olarak görülen turizm sektöründeki şokların etkisinin kalıcı mı yoksa geçici mi olacağının tespiti son derece önemlidir. Do- layısıyla şokların etkisi kalıcı ise yapılan yatırımların geri dönüş süresi uzamakta ve turizmden elde edilmesi beklenen gelirler kaybedilebilmekte veya sağlanan kazançların sürdürülebilirliği tehlikeye girebilmektedir. Tam tersi durumda ise ekonomik açıdan herhangi bir olumsuz durum söz konusu olmayarak, yapılan yatırımların geri dönüş süresi uzamamakta, turizmden beklenen gelirler elde edilebilmekte ve sağlanan kazançların sürdürülebilirliği tehlikeye girmemektedir. Bu noktada, şokların kalıcı mı yoksa geçici mi olup olmadığının belirlenmesi, Türkiye'nin turizm sektöründen elde edeceği gelirlerin sürekliliğinin tespiti açısından büyük önem arz etmektedir.

Sonuç olarak bu çalışmanın temel amacı, Türk turizm sektörü için talep şoklarının geçici mi yoksa kalıcı mı olduğunu analiz etmektir ve bu kapsamda Türkiye'ye en çok turist gönderen 23 ülke için 1991-2010 dönemini kapsayan bir panel veri seti oluşturulmuş ve panel birim kök analizleri yapılmıştır. Yapılan birim kök analizleri sonucunda Türk turizm sektöründe talep şoklarının geçici olduğu sonucuna ulaşılmıştır. Bu yönüyle söz konusu bu çalışma Türk turizm sektöründe talep şoklarının tanımlanması ve etkilerinin analizi noktasında öncül bir çalışma olma niteliği taşımaktadır.

Ek-1. Milliyetlerine Göre Türkiye'ye gelen Turistlerin Sayıları (ita) ve Turizm Talep Şokları $\left(\varepsilon_{t}^{i t a}\right)$

\begin{tabular}{|c|c|c|c|c|c|c|c|c|c|}
\hline Ülkeler & Yıllar & $\begin{array}{c}\text { ita } \\
\text { Turizm Talebi }\end{array}$ & $\ln \delta_{i t a, t}$ & $\varepsilon_{t}^{i t a}$ & Ülkeler & Yıllar & $\begin{array}{c}\text { ita } \\
\text { Turizm Talebi }\end{array}$ & $\ln \delta_{i t a, t}$ & $\varepsilon_{t}^{i t a}$ \\
\hline Almanya & 1991 & 779882 & 13,566898 & 2,62 & Avusturya & 1991 & 102071 & 11,533424 & 0,58 \\
\hline Almanya & 1996 & 2141778 & 14,577147 & 3,19 & Avusturya & 1996 & 235540 & 12,369636 & 0,99 \\
\hline Almanya & 2001 & 2884051 & 14,874706 & 3,06 & Avusturya & 2001 & 360363 & 12,794867 & 0,98 \\
\hline Almanya & 2006 & 3762475 & 15,140588 & 2,89 & Avusturya & 2006 & 429709 & 12,970864 & 0,72 \\
\hline Almanya & 2010 & 4385263 & 15,29376 & 2,70 & Avusturya & 2010 & 500321 & 13,123005 & 0,53 \\
\hline Belçika & 1991 & 33763 & 10,427121 & $-0,52$ & Bulgaristan & 1991 & 943250 & 13,757087 & 2,81 \\
\hline Belçika & 1996 & 113505 & 11,639602 & 0,26 & Bulgaristan & 1996 & 139301 & 11,844392 & 0,46 \\
\hline Belçika & 2001 & 310296 & 12,645282 & 0,83 & Bulgaristan & 2001 & 540452 & 13,200161 & 1,39 \\
\hline Belçika & 2006 & 459824 & 13,038599 & 0,79 & Bulgaristan & 2006 & 1177906 & 13,979249 & 1,73 \\
\hline Belçika & 2010 & 543003 & 13,20487 & 0,61 & Bulgaristan & 2010 & 1433970 & 14,175957 & 1,58 \\
\hline Çek Cumhuriyeti & 1991 & 217232 & 12,288721 & 1,34 & Danimarka & 1991 & 32320 & 10,383442 & $-0,57$ \\
\hline Çek Cumhuriyeti & 1996 & 40929 & 10,619594 & $-0,76$ & Danimarka & 1996 & 147531 & 11,901794 & 0,52 \\
\hline Çek Cumhuriyeti & 2001 & 51818 & 10,855493 & $-0,96$ & Danimarka & 2001 & 126034 & 11,744307 & $-0,07$ \\
\hline Çek Cumhuriyeti & 2006 & 94450 & 11,455826 & $-0,79$ & Danimarka & 2006 & 235755 & 12,370548 & 0,12 \\
\hline Çek Cumhuriyeti & 2010 & 174426 & 12,069256 & $-0,52$ & Danimarka & 2010 & 314446 & 12,658568 & 0,07 \\
\hline
\end{tabular}


1. Milliyetlerine Göre Türkiye'ye gelen Turistlerin Sayıları (ita) ve Turizm Talep Şokları $\left(\varepsilon_{t}^{i t a}\right)$

\begin{tabular}{|c|c|c|c|c|c|c|c|c|c|}
\hline Ülkeler & Yıllar & $\begin{array}{c}\text { ita } \\
\text { Turizm Talebi }\end{array}$ & $\ln \delta_{i t a, t}$ & $\varepsilon_{t}^{i t a}$ & Ülkeler & Yıllar & $\begin{array}{c}\text { ita } \\
\text { Turizm Talebi }\end{array}$ & $\ln \delta_{i t a, t}$ & $\varepsilon_{t}^{i t a}$ \\
\hline Finlandiya & 1991 & 80511 & 11,296149 & 0,34 & Fransa & 1991 & 117070 & 11,670527 & 0,72 \\
\hline Finlandiya & 1996 & 124627 & 11,733081 & 0,35 & Fransa & 1996 & 251976 & 12,437089 & 1,05 \\
\hline Finlandiya & 2001 & 64283 & 11,07105 & $-0,74$ & Fransa & 2001 & 524170 & 13,169571 & 1,35 \\
\hline Finlandiya & 2006 & 78766 & 11,274237 & $-0,97$ & Fransa & 2006 & 657859 & 13,396746 & 1,15 \\
\hline Finlandiya & 2010 & 143204 & 11,872025 & $-0,72$ & Fransa & 2010 & 928376 & 13,741192 & 1,15 \\
\hline Hollanda & 1991 & 107018 & 11,580752 & 0,63 & İngiltere & 1991 & 200813 & 12,210129 & 1,26 \\
\hline Hollanda & 1996 & 216672 & 12,28614 & 0,90 & Ingiltere & 1996 & 758433 & 13,53901 & 2,16 \\
\hline Hollanda & 2001 & 632975 & 13,358186 & 1,54 & İngiltere & 2001 & 845536 & 13,647726 & 1,83 \\
\hline Hollanda & 2006 & 997556 & 13,813064 & 1,57 & Ingiltere & 2006 & 1678845 & 14,333617 & 2,09 \\
\hline Hollanda & 2010 & 1073064 & 13,886029 & 1,29 & İngiltere & 2010 & 2673605 & 14,798938 & 2,21 \\
\hline İrlanda & 1991 & 11736 & 9,3704163 & $-1,58$ & İspanya & 1991 & 24944 & 10,124389 & $-0,83$ \\
\hline İrlanda & 1996 & 24431 & 10,103608 & $-1,28$ & İspanya & 1996 & 47617 & 10,770945 & $-0,61$ \\
\hline İrlanda & 2001 & 48635 & 10,792099 & $-1,02$ & İspanya & 2001 & 116067 & 11,661923 & $-0,15$ \\
\hline İrlanda & 2006 & 88973 & 11,396088 & $-0,85$ & İspanya & 2006 & 234334 & 12,364503 & 0,12 \\
\hline İrlanda & 2010 & 111065 & 11,617871 & $-0,97$ & İspanya & 2010 & 321325 & 12,680208 & 0,09 \\
\hline İsveç & 1991 & 69344 & 11,146835 & 0,20 & İsviçre & 1991 & 41606 & 10,636 & $-0,32$ \\
\hline İsveç & 1996 & 163944 & 12,00728 & 0,62 & İsviçre & 1996 & 70961 & 11,169886 & $-0,21$ \\
\hline İsveç & 2001 & 200709 & 12,209611 & 0,39 & İsviçre & 2001 & 126538 & 11,748298 & $-0,07$ \\
\hline İsveç & 2006 & 326254 & 12,695431 & 0,45 & İsviçre & 2006 & 210277 & 12,256181 & 0,01 \\
\hline İsveç & 2010 & 447270 & 13,010918 & 0,42 & İsviçre & 2010 & 271139 & 12,510387 & $-0,08$ \\
\hline İtalya & 1991 & 64134 & 11,06873 & 0,12 & İzlanda & 1991 & 3398 & 8,1309423 & $-2,82$ \\
\hline İtalya & 1996 & 160118 & 11,983666 & 0,60 & İzlanda & 1996 & 4574 & 8,4281434 & $-2,96$ \\
\hline İtalya & 2001 & 315286 & 12,661235 & 0,85 & İzlanda & 2001 & 4110 & 8,3211783 & $-3,49$ \\
\hline İtalya & 2006 & 402568 & 12,905619 & 0,66 & İzlanda & 2006 & 6667 & 8,8049253 & $-3,44$ \\
\hline İtalya & 2010 & 671060 & 13,416614 & 0,82 & İzlanda & 2010 & 6476 & 8,7758583 & $-3,82$ \\
\hline Lüksemburg & 1991 & 1608 & 7,3827464 & $-3,57$ & Macaristan & 1991 & 164903 & 12,013113 & 1,06 \\
\hline Lüksemburg & 1996 & 1762 & 7,4742048 & $-3,91$ & Macaristan & 1996 & 15428 & 9,6439393 & $-1,74$ \\
\hline Lüksemburg & 2001 & 3527 & 8,1682029 & $-3,65$ & Macaristan & 2001 & 38194 & 10,550434 & $-1,26$ \\
\hline Lüksemburg & 2006 & 5365 & 8,5876517 & $-3,66$ & Macaristan & 2006 & 78275 & 11,267984 & $-0,98$ \\
\hline Lüksemburg & 2010 & 11262 & 9,3291895 & $-3,26$ & Macaristan & 2010 & 90944 & 11,417999 & $-1,17$ \\
\hline Norveç & 1991 & 24590 & 10,110095 & $-0,84$ & Polonya & 1991 & 184008 & 12,122735 & 1,17 \\
\hline Norveç & 1996 & 86751 & 11,370797 & $-0,01$ & Polonya & 1996 & 37542 & 10,533216 & $-0,85$ \\
\hline Norveç & 2001 & 87704 & 11,381723 & $-0,43$ & Polonya & 2001 & 150916 & 11,924479 & 0,11 \\
\hline Norveç & 2006 & 165580 & 12,01721 & $-0,23$ & Polonya & 2006 & 190774 & 12,158845 & $-0,09$ \\
\hline Norveç & 2010 & 299405 & 12,609552 & 0,02 & Polonya & 2010 & 428275 & 12,967521 & 0,38 \\
\hline Portekiz & 1991 & 3197 & 8,0699681 & $-2,88$ & Romanya & 1991 & 503785 & 13,129905 & 2,18 \\
\hline Portekiz & 1996 & 9728 & 9,1827636 & $-2,20$ & Romanya & 1996 & 191511 & 12,162701 & 0,78 \\
\hline
\end{tabular}


Talep Şokları: Türk Turizm Sektörü İçin Bir Analiz

1. Milliyetlerine Göre Türkiye'ye gelen Turistlerin Sayıları (ita) ve Turizm Talep Şokları $\left(\varepsilon_{t}^{i t a}\right)$

\begin{tabular}{|c|c|c|c|c|c|c|c|c|c|}
\hline Ülkeler & Yıllar & $\begin{array}{c}\text { ita } \\
\text { Turizm Talebi }\end{array}$ & $\ln \delta_{i t a, t}$ & $\varepsilon_{t}^{i t a}$ & Ülkeler & Yıllar & $\begin{array}{c}\text { ita } \\
\text { Turizm Talebi }\end{array}$ & $\ln \delta_{i t a, t}$ & $\varepsilon_{t}^{i t a}$ \\
\hline Portekiz & 2001 & 18382 & 9,8191272 & $-2,00$ & Romanya & 2001 & 180911 & 12,10576 & 0,29 \\
\hline Portekiz & 2006 & 18148 & 9,8063156 & $-2,44$ & Romanya & 2006 & 245941 & 12,412847 & 0,17 \\
\hline Portekiz & 2010 & 53373 & 10,88506 & $-1,71$ & Romanya & 2010 & 355144 & 12,780279 & 0,19 \\
\hline Yunanistan & 1991 & 138918 & 11,841639 & 0,89 & & & & & \\
\hline Yunanistan & 1996 & 147305 & 11,900261 & 0,52 & & & & & \\
\hline Yunanistan & 2001 & 197258 & 12,192268 & 0,38 & & & & & \\
\hline Yunanistan & 2006 & 413162 & 12,931595 & 0,68 & & & & & \\
\hline Yunanistan & 2010 & 670297 & 13,415476 & 0,82 & & & & & \\
\hline
\end{tabular}

Kaynak: www.kultur.gov.tr/

Not: Turizm talebi verileri, T.C. Kültür ve Turizm Bakanlığı'nın Turizm İstatistikleri veri tabanından elde edilmiş veriler olup ve değerleri yazarlar tarafından hesaplanmıştır.

\section{KAYNAKÇA}

Bahar, O. (2006). Turizm Sektörünün Türkiye'nin Ekonomik Büyümesi Üzerindeki Etkisi: Var Analizi Yaklaşımı, Celal Bayar Üniversitesi I.I.B.F. Yönetim ve Ekonomi Dergisi, 13 (2): 137-150.

Bahar, O. (2006). Türkiye'nin İktisadi Gelişiminde Turizm Sektörüne Sağlanan Teşviklerin Rolü: Uygulamalı Bir Araştırma, İktisat, İsletme ve Finans Dergisi, 241: 128-139.

Bahar, O. (2010). Turizm Sektörüne Sağlanan Doğrudan Yabanc1 Sermaye Yatırımlarının (DYSY) Ekonomik Büyüme Üzerine Olan Olası Etkisi: Türkiye Örneği (1986-2006), Anatolia: Turizm Araştırmaları Dergisi, 21 (1): 27-40.ᄀ

Bahar, O. ve Kozak M. (2007). Advancing Destination Competitiveness Research: Comparison Between Tourists and Service Providers, Journal of Travel and Tourism Marketing, 22 (2): 61-71.

Bahar, O. ve Bozkurt, K. (2010). Gelişmekte Olan Ülkelerde Turizm-Ekonomik Büyüme İlişkisi: Dinamik Panel Veri Analizi, Anatolia: Turizm Araştırmaları Dergisi, 21 (2): 1-11.

Bhattacharya, M. ve Narayan, P. K. (2005). Testing for the Random Walk Hypothesis in the Case of Visitor Arrivals: Evidence from Indian Tourism, Applied Economics, 37: 1485-1490.

Breusch, T. S ve Pagan, A. R. (1980). The Lagrange Multiplier Test and Its Applications to Model Specification Tests in Econometrics, Review of Economic Studies, 47: 239-253.

Choi, I. (2001). Unit Roots Tests for Panel Data, Journal of International Money and Finance, 20: 229-272.

Gökovalı, U. ve Bahar, O. (2006). Contribution of Tourism to Economic Growth in Mediterrranean Countries: A Panel Data Approach, Anatolia An International Journal of Tourism And Hospitality Research, 17 (2): 155-168.

Hadri, K. (2000). Testing for Stationarity in Heterogenous Panels, Econometrics Journal, 3: 148-161.

Im, K. S., Pesaran, H. ve Shin, Y. (1997). Testing for Unit Roots in Heterogenous Panels, http://www.econ.cam.ac.uk/faculty/ pesaran/lm.pdf, Erişim tarihi: 16.10.2013.
Im, K. S., Pesaran, H. ve Shin, Y. (2003). Testing for Unit Roots in Heterogenous Panels, Journal of Econometrics, 115 (1): 53-74.

Kozak, M., Baloğlu, Ş. ve Bahar O. (2010). Measuring Destination Competitiveness: Multiple Destinations vs Multiple Nationalities, Journal of Hospitality Marketing E Management, 19 (1): 56-71.

Lee, C. G. (2009). Are Tourist Arrivals Stationary? Evidence from Singapore, International Journal of Tourism Research. 11: $1-6$.

Levin, A. ve Lin, C. (1992). Unit Roots Tests in Panel Data: Asymptotic and Finite Sample Properties. University of CaliforniaSan Diego Discussion Paper, No: 92-23.

Levin, A. ve Lin, C. (1993). Unit Roots Tests in Panel Data: New Result. University of California-San Diego Discussion Paper, No: 93-56.

Maddala, G. S. ve Wu, S. (1997). A Comparative Study of Unit Root Tests with Panel Data and A New Simple Test. Ohio State University Working Paper.

Narayan P. K. (2011). Are Shocks to Tourism Transitory at Business Cycle Horizons? Applied Economics, 43: 2071-2077.

Narayan, P. K. (2005). The Structure of Tourist Expenditure in Fiji: Evidence from Unit Root Structural Break Tests, Applied Economics, 37: 1157-1161.

Narayan, P. K. (2008). Examining the Behaviour of Visitor Arrivals to Australia from 28 Different Countries, Transportation Research Part A: Policy and Practice, 42 (5): 751-761.

Narayan, P. K. ve Prasad, A. (2008). Examining the Behaviour of Visitor Arrivals to Australia from Twenty Different Countries: An Application Of Panel Unit Root Tests, Economic Papers, 27 (3): 265-271.

Pesaran, M. H. (2004). General Diagnostic Tests for Cross Section Dependence in Panels. Cambridge Working Papers in Economics, No: 0435.

Pesaran, M. H. (2006). A Simple Panel Unit Root Test in The Presence of Cross Section Dependence. Cambridge Working Papers in Economics, No: 0346. 
Pesaran, M. H. ve Yamagata, T. (2008). Testing Slope Homogeneity in Large Panels, Journal of Econometrics, 142 (1): 50-93.

Sivri, U. (2010). Şokların Yabancı Ziyaretçi Sayısı ve Yabancı Ziyaretçi Harcamaları Üzerindeki Etkisi Kalıcı Mıdır? TISK Akademi Dergisi, 5 (10): 220-237.

Smyth, R., Nielsen, I. ve Mishra, V. (2009). I've been to Bali too' (And I Will Be Going Back): Are Terrorist Shocks To Bali's Tourist Arrivals Permanent or Transitory?, Applied Economics, 41 (11): 1367-1378.

WTO (World Tourism Organization) (2011). Tourism Highlights. Spain.
World Tourism Organization. 2014. Tourism Highlights 2014 Edition, Spain.

www.kultur.gov.tr/, (Erişim Tarihi: 15 Aralık 2013).

www.tursab.org.tr, (Erişim Tarihi: 15 Aralık 2013).

Yılgör, M. (2008). OECD Ülkelerinde İkiz Açık Teorisinin Panel Veri Modelleri İle İncelenmesi (Yayınlanmamış Doktora Te$z i)$ İstanbul: Marmara Üniversitesi, Sosyal Bilimler Enstitüsü, Ekonometri Anabilim Dalı, Ekonometri Bilim Dalı. 